\title{
Diagnostic Test Validity of MCV for Determination of Thalassaemia Carrier in Bangladesh
}

\author{
Nazmul Haque1, Narayan Chandra Saha², M. Ekhlasur Rahman², \\ Tahmina Ahmed ${ }^{4}$ \\ ${ }^{1}$ Assistant Professor, Department of Paediatric Neurology, National Institute of Neurosciences \& Hospital, \\ Dhaka, Bangladesh; ${ }^{2}$ Professor \& Head, Department of Paediatric Neurology, National Institute of \\ Neurosciences \& Hospital, Dhaka, Bangladesh; ${ }^{3}$ Former Head, Department of Paediatrics, \\ Dhaka Medical College, Bangladesh; ${ }^{4}$ Junior Consultant (Gynaecology), Kurmitola \\ General Hospital, Dhaka, Bangladesh
}

[Received: 12 February 2016; Revised: 3 March 2016; Accepted: 19 May 2016; Published: 1 July 2016]

\begin{abstract}
Background: Mean corpuscular volume (MCV) and mean corpuscular haemoglobin (MCH) of red blood cell is the useful diagnostic test which is performed during routine blood examination. Objective: The purpose of the present study was to measure the diagnostic test validity of MCV for the determination of thalassaemia carrier. Methodology: This analytic cross-sectional study was carried out in the Department of Pediatrics and Department of Medicine at MAG Osmani Medical College Hospital, Sylhet, Bangladesh from September 2007 to January 2009 for a period of one year and five months. Siblings and cousins of beta Thalassemia major and $\mathrm{Hb}$ - E -beta Thalassemia satisfying the selection criteria were enrolled. The detailed history and thorough physical examination were done meticulously. Five (5) $\mathrm{mL}$ blood was drawn from each case and control for determination of MCV and Hb-Electrophoresis. Result: Total 63 were enrolled as cases and total 65 were enrolled as controls. Sensitivity, specificity, positive and negative predictive value of $\mathrm{MCV}$ in determination of thalassemic carriers were $92 \%, 89.2 \%, 89.2 \%$ and $92 \%$ respectively. The area under the curve value was 0.094 (0.035 to 0.152 ). Conclusion: In conclusion the diagnostic test validity of $\mathrm{MCH}$ and $\mathrm{MCH}$ is high in determination of Thalassemic carrier. [Journal of National Institute of Neurosciences Bangladesh, 2016;2(2): 94-97]
\end{abstract}

Keywords: Diagnostic test; validity; mean corpuscular volume; mean corpuscular haemoglobin

Correspondence: Dr. Nazmul Haque, Assistant Professor, Department of Paediatric Neurology, National Institute of Neurosciences \& Hospital, Sher-E-Bangla Nagar, Agargaon, Dhaka-1207, Bangladesh; Email: nazmulk51@gmail.com; Cell no.: +8801830008498 Conflict of interest: There is no conflict of interest to any of the authors of this article.

Funding agency: The study was not funded by any authority.

Contribution to authors: N Haque, NC Saha, ME Rahman and T Ahmed were involved in protocol preparation, data collection and literature search up to report writing. N Haque was involved in manuscript preparation as well as involved in literature search up and manuscript revision and also in statistical analysis.

How to cite this article: Haque N, Saha NC, Rahman ME, Ahmed T. Diagnostic Test Validity of MCV for Determination of Thalassaemia Carrier in Bangladesh. J Natl Inst Neurosci Bangladesh 2016;2(2): 94-97

Copyright: (C2016 Haque et al. Published by Journal of National Institute of Neurosciences Bangladesh. This article is published under the Creative Commons CC BY-NC License (https://creativecommons.org/licenses/by-nc/4.0/). This license permits use, distribution and reproduction in any medium, provided the original work is properly cited, and is not used for commercial purposes.

\section{Introduction}

Hemoglobinopathies are a major health problem in many areas of the world ${ }^{1}$. Two of the most prevalent hemoglobinopathies are sickle hemoglobin $(\mathrm{HbS})$ and beta thalassemia. Thalassemia is a molecular abnormality with underproduction of one of the globin chains $^{2}$. In Bangladesh 7\% population is thalassemic carrier $^{3}$. Determination of Thalassemic carrier is the mainstay of prevention.

Red cell indices provide valuable tool for preliminary screening of thalassemia traits. Thalassemic traits in general have reduced mean corpuscular volume (MCV) and reduced mean corpuscular hemoglobin $(\mathrm{MCH})$ with normal mean corpuscular hemoglobin concentration (MCHC). Specific cut off points for each index varies from laboratory to laboratory. Some laboratories 
concentrate on both reduced $\mathrm{MCV}$ and $\mathrm{MCH}$ and some on $\mathrm{MCV}$ or $\mathrm{MCH}$ alone $\mathrm{s}^{5}$ The purpose of the present study was to determine sensitivity, specificity, positive \& negative predictive values of $\mathrm{MCV}$ in the determination of thalassemic carrier like beta thalassemia major and haemoglobin $\mathrm{E}$ beta thalassemia.

\section{Methodology}

This present study was designed as analytical cross-sectional study. This study was carried out in the Department of Pediatrics and Department of Medicine of Sylhet MAG Osmani Medical College Hospital, Sylhet, Bangladesh from September 2007 to January 2009 for a period of one year and four months. The siblings and cousins of diagnosed cases of beta thalassaemia major and $\mathrm{Hb} \mathrm{E}$ beta thalassaemia with the age group of 1 to $20 \mathrm{yrs}$ who were presented with the HbA2 level more than 3.5\% were selected as case group and those who were presented with $\mathrm{HbA} 2$ less than $3.5 \%$ were selected as control group. Iron deficiency anemia diagnosed clinically by moderate to severe pallor, angular stomatitis, smooth tongue, koilonychias, hepatomegaly and subjects below 1 year were excluded from this study. Both case and control groups were selected by systematic random sampling by choosing every 2 nd case. Siblings aging more than 1 year, first degree cousins of the patient diagnosed as beta thalassemia, E-beta thalassaemia by $\mathrm{Hb}$-Electrophoresis were interviewed and detailed history was taken and thorough physical examination were done; $5 \mathrm{ml}$ blood was taken for $\mathrm{MCV}$ measurement and $\mathrm{Hb}$-electrophoresis. Two (2) $\mathrm{mL}$ was introduced into automated cell counter in haematology laboratory of private diagnostic centre in Sylhet (Medinova Medical Service Ltd., Sylhet and Popular Diagnostic Center Ltd., Sylhet) for MCV \& MCH and three (3) $\mathrm{mL}$ anti-coagulated blood was sent to Dhaka in two private diagnostic laboratories (Medinova Medical Service Ltd., Dhanmondi, Dhaka and Popular Diagnostic Center Ltd., Dhanmondi, Dhaka) by air incubated in freeze for $\mathrm{Hb}$ electrophoresis. MCV test was carried out by SYSMEX XT1800i cell counter. Hemoglobin electrophoresis is carried out by Serbia Automated System on agarose gel (Hydragel). Controls were also investigated for MCV and $\mathrm{Hb}$-Electrophoresis. Sensitivity, Specificity, positive and negative predictive values were calculated. Data were collected by a structured questionnaire were analyzed and interpreted duly using computer software SPSS 20.0. Informed written consent was taken before data collection. Permission from the local Ethical committee of SMAGMOC was taken.

\section{Results}

A total number of 128 subjects were recruited for this study of which 63 subjects were in case group and the rest 65 subject were in control group. MCV in cases and control group were $68.2 \pm 2.3 \mathrm{fl}$ and $86.2 \pm 3.2 \mathrm{fl}$ respectively. There was no significant difference between case \& control group in $\mathrm{MCV}(\mathrm{p}=0.995)$ (Table 1).

Table 1: Mean Values of MCV among the Study Population $(\mathrm{n}=128)$

\begin{tabular}{lccc}
\hline Variables & \multicolumn{2}{c}{ Group } & Pvalue \\
Mean \pm SD) & Case & Control & \\
\hline $\mathrm{MCV}(\mathrm{fl})$ & $68.2 \pm 2.3$ & $86.2 \pm 3.2$ & 0.995 \\
\hline
\end{tabular}

$\mathrm{fl}=$ femtolitre,

Among the 63 cases MCV was positive in 58(92.1\%) cases and negative in 5(7.9\%) cases. Again, among 65 control group $\mathrm{MCV}$ was positive and negative in $7(10.8 \%)$ cases and $58(89.2 \%)$ cases respectively. The association between these two group was statistically significant $(\mathrm{p}=0.0001)$ (Table 2).

Table 2: Comparison of MCV and Hb-Electrophoresis for Detection of Thalassaemia Carriers $(n=128)$

\begin{tabular}{lcccl}
\hline MCV & Case & Control & Total & P value \\
\hline Positive & $58(92.1 \%)$ & $7(10.8 \%)$ & $65(50.8 \%)$ & \\
Negative & $5(7.9 \%)$ & $58(89.2 \%)$ & $63(49.2 \%)$ & 0.0001 \\
Total & $\mathbf{6 3}(\mathbf{1 0 0 . 0} \%)$ & $\mathbf{6 5 ( 1 0 0 . 0 \% )}$ & $\mathbf{1 2 8}(\mathbf{1 0 0 . 0} \%)$ & \\
\hline
\end{tabular}

Sensitivity and Specificity of MCV in the diagnosis of thalassemic carriers were found $92 \%$ and $89.2 \%$ respectively \& were high. The Positive predictive value and Negative predictive value of MCV in the diagnosis of thalassemic carriers were found $89.2 \%$ and $92 \%$ respectively (Table 3 ).

Table 3: Diagnostic Test Validity of MCV for Detection of Thalassaemia Carriers

\begin{tabular}{lcc}
\hline Variables & Values & 95\% CI \\
\hline Sensitivity & $92.0 \%$ & 82.4 to $97.4 \%$ \\
Specificity & $89.2 \%$ & 79.1 to $95.6 \%$ \\
Positive Predictive Value & $89.2 \%$ & 80.4 to $94.4 \%$ \\
Negative Predictive Value & $92.0 \%$ & 83.3 to $96.4 \%$ \\
Accuracy & $90.6 \%$ & 85.5 to $95.7 \%$ \\
\hline
\end{tabular}

*95\% CI $=95 \%$ Confidence Interva

\section{Discussion}

It is very difficult task to detect the thalassemic carrier by screening test ${ }^{6}$. These are related to the heterogeneity of beta thalassaemia. The absence of a 
single test is still a scarcity to cover all beta-thalassemia variants. It has been well established that the most accurate tests for the detection of thalassemic carriers are genetic detection and globin chain determination ${ }^{7}$. Both of which are either very expensive or not available for screening programs in third world countries like Bangladesh ${ }^{8}$.

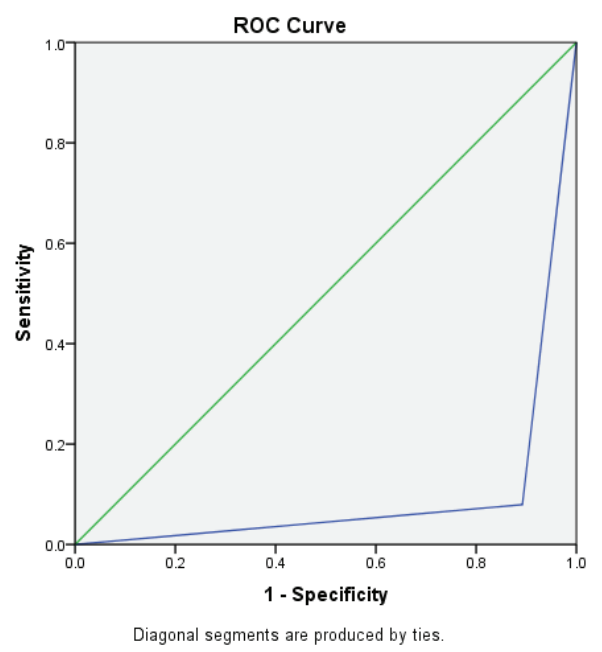

Figure I: The ROC curve for MCV value for Detection of Thalassaemia Carriers

Carrier diagnosis involves the accurate measurement of $\mathrm{MCV}, \mathrm{MCH}, \mathrm{HbA} 2$ and $\mathrm{HbF}$ values ${ }^{9}$. Thalassemic traits in general have reduced mean corpuscular volume $(\mathrm{MCV}) . \mathrm{MCV}$ is used in determination of thalassemic carrier in high rate $^{10}$. The present descriptive study showed that MCV alone was 92\% sensitive, $98.2 \%$ specific, positive predictive value was $89.2 \%$ and negative predictive value was $92 \%$ for determination of thalassemic carriers which is considered high. A similar study was performed on 1286 antenatal women in India using MCV $(<77 \mathrm{fl})$ for determination of thalassemic carrier, where sensitivity and specificity was $98 \%$ and $92 \%$ respectively ${ }^{11}$. The increased sensitivity in this study group is probably due to large sample size and selective study group (women). The result of this study supports the result of current study.

During the past few years, several new discoveries mostly arising from human patients or mouse models have highlighted the implication of iron metabolism. Components in hereditary microcytic anemia are transported from intestinal absorption to its final inclusion into heme ${ }^{12}$. Degree of reduction of $\mathrm{MCV}$ and $\mathrm{MCH}$ in iron deficiency tends to parallel the severity of the anemia which contrasts with most cases of heterogygous thalassemia in which the MCV and $\mathrm{MCH}$ are disproportionately low $^{13}$
Table 4: Value of Area Under the Curve of MCV value for Detection of Thalassaemia Carriers

\begin{tabular}{cccc}
\hline Area & $\begin{array}{c}\text { Asymptotic } \\
\text { Sig. }^{b}\end{array}$ & \multicolumn{2}{c}{ Asymptotic 95\% Confidence Interval } \\
\cline { 3 - 4 } & 0.0001 & 0.035 & Upper Bound \\
\hline 0.094 & $0.00 u n d$ & 0.152 \\
\hline
\end{tabular}

*The test result variable(s): $\mathrm{MCH}$ _MCV has at least one tie between the positive actual state group and the negative actual state group. Statistics may be biased; a. Under the nonparametric assumption; b. Null hypothesis: true area $=$ 0.5

However, it may be recalled that another method of carrier detection is NESTROFT (Naked eye single tube red cell osmotic fragility test). In a recent survey in India on 1048 antenatal women sensitivity specificity, positive and negative predicative values of NESTROFT were 91.0\%, 95.0\%, 55.0\%, 99.0\% respectively ${ }^{14}$. The result of this study has similar result with the current study. A hospital based descriptive study was performed where sensitivity, specificity, positive and negative predictive values of NESTROFT were $94.3 \%, 88.6 \%, 89.1 \%$ and $94.0 \%$; these findings are in conformity with the result of current study ${ }^{15}$.

This present study has some limitations. Study was carried out in Sylhet where Hb electrophoresis facility is not available. Transportation of blood sample might cause some alteration of result. Sample was selected from hospital relation and sample size was small. Furthermore, iron deficiency anemia can't be excluded by laboratory test by RDW due to more financial burden on the study. The study includes cousins and siblings of both beta thalassemia major and $\mathrm{Hb}$-E- beta thalassemia. Hb-E electrophoresis facility is not available in Sylhet, available only in Dhaka city of Bangladesh during the study period.

\section{Conclusion}

In conclusion sensitivity, specificity and predictive values of $\mathrm{MCV}$ is high in detection of thalassemic carriers like beta thalassemia major and $\mathrm{Hb}-\mathrm{E}$ beta thalassemia in the age range of 1 year to 20 years. Further large scale study should be carried out to see the real scenario of the validity of the test.

\section{References}

1. Goljan E. Pathology, 2nd ed, Mosby Elsevier, Rapid Review Series. New York, 2002;298-299

2. Model B. Update of Epidemiology of hemoglobin disorders with special references to thalassaemia. Thalassemia International Federation 2003;16:122-127

3. WHO guidelines for control of hemoglobin disorders, Unpublished Document WHO/ HDP/HB/GI/94. Obtainable free 
of charge from the hereditary Disease programme, WHO, Geneva, Switzerland, 2001;79:8

4. Tosun F, Bilgin A, Kizilok A, Arpaci A, Yuregir G.T. Premarital screening program in Mersin, Turkey. Turk J Hematology 2006;23

(2):84-89

5. Weatherall DJ, Letsky EA. Genetic haematological disorder Antenatal and neonatal screening. Oxford. Oxford University Press. 2000: P-243

6. Khan WA. Thalassemia in Bangladesh. DS (children) H Journal 1999; 15(1):42-44

7. Legatt DD, Shalapay CM. Project list; capital health 2007:407:1411

8. Angastiniotis M. Thalassemia Epidemiology and prevention. European Genetic Foundation 2008;1:104-106

9. Hassan MY, Johnston JM, Windle ML. Thalassemia. Medscape
Journal 2007;3:137-41

10. Anthony SF, Eugene B. Principals of Harrison's Internal Medicine, 17th edition. New York McGraw Hill 2008:64

11. Mehta BC. NESTROFT; A screening test for beta thalassemia trait. Indian J Med Sci 2002;56(11):537-44

12. Khan MR, Rahman ME. Essence of Pediatrics, 3rd edition. Dhaka; 2004, p-698-700

13. Old JM. Screening and genetic diagnosis of hemoglobin disorders. Blood Rev 2003;17(1):43-53

14. Iolascon A, Defalcol L, Beaumont C. Molecular basis of inherited microcytic anemia due to defects in iron acquisition or heme synthesis. Haematologica 2009;94(3):395-408

15. Islam A. Validity of NESTROFT in screening of beta thalassemia trait. [MD Thesis]. BSM Medical University, Dhaka; 2009;61 